\title{
Biological significance of FoxN1 gain-of-function mutations during $T$ and $B$ lymphopoiesis in juvenile mice
}

\author{
L Ruan ${ }^{1,2,3}$, Z Zhang ${ }^{2,3}$, L Mu², P Burnley ${ }^{2}$, L Wang ${ }^{2}$, B Coder $^{2}$, Q Zhuge ${ }^{*, 1}$ and D-M Su*,1,2
}

FoxN1 is cell-autonomously expressed in skin and thymic epithelial cells (TECs), essential for their development. Inborn mutation of FoxN1 results in hair follicle and TEC development failure, whereas insufficient postnatal FoxN1 expression induces thymic atrophy, resulting in declined $\mathrm{T}$ lymphopoiesis. Although upregulating FoxN1 expression in the aged FoxN1-declined thymus rejuvenates $\mathrm{T}$ lymphopoiesis, whether its over- and ectopic-expression in early life is beneficial for $\mathrm{T}$ lymphopoiesis is unknown. Using our newly generated Rosa26-STOP ${ }^{\text {flox }}$-FoxN1 mice, in which over- and ectopic-expression of FoxN1 can be induced by various promoter-driven Cre-mediated deletions of the roadblock STOP $P^{\text {flox }}$ in early life, we found that K14Cre-mediated inborn FoxN1 overexpression induced neonatal lethality, exhibited abnormal permeability in the skin and abnormal nursing. Ubiquitous deletion of the STOP ${ }^{\text {flox }}$ mediated by progressive $\mathrm{UCreER}^{\top}$ leakage in juvenile mice affected thymus and bone marrow normality, resulting in an increased ratio of medullary/cortical TECs, along with declined T and B lymphopoiesis. Although the $\mathrm{K}^{2} \mathrm{CreER}^{\mathrm{T}}$ mediated FoxN1 overexpression mice had a normal lifespan, induction of $\mathrm{K} \mathrm{CreER}{ }^{\top}$ activation in juveniles adversely influenced total thymoycte development and produced ichthyosis-like skin. Therefore, FoxN1 has temporal and tissue-specific activity. Overand ectopic-expression of FoxN1 in early life adversely influence immature TEC, T and B cell, and skin epithelial development. Cell Death and Disease (2014) 5, e1457; doi:10.1038/cddis.2014.432; published online 9 October 2014

Transcription factor FoxN1 is an epithelial cell-autonomous gene, predominantly regulating development of thymic epithelial cells (TECs) and skin keratinocytes. ${ }^{1}$ Inborn FoxN1 mutation results in thymic and hair follicle epithelial development failure ${ }^{2-4}$ associated with primary immune deficiency ${ }^{5-7}$ and hairless nude skin. ${ }^{8-10}$ Insufficient FoxN1 expression in postnatal life results in accelerated thymic aging. ${ }^{11-13}$ Although elevating FoxN1 expression in the aged thymus can reinstate TEC homeostasis and induce thymic functional rejuvenation, ${ }^{12,14,15}$ whether FoxN1 activity is sensitive to genetic dosage, tissue, and temporal-specificity is still unclear. Mounting evidence shows that dosage of FoxN1 is indeed important for postnatal thymic homeostasis. When dosage of FoxN1 is slightly elevated or depressed, the status of the postnatal thymus is significantly influenced. It is known that the thymus in wild-type (WT) young mice with a full dosage of FoxN1 is completely normal, whereas it is completely abnormal in FoxN1-null (inborn mutation, termed ' $\left.n u / n u^{\prime}\right)$ nude mice. In between these two extremes, the FoxN1-null heterozygote (nu/+) mouse has a $50 \%$ reduced genetic dosage compared to its WT littermates. Although the $50 \%$ dosage of FoxN1 is sufficient to induce TEC patterning ${ }^{4}$ during thymic organogenesis, the nu/+ mice have certain defects in thymic size and thymocyte number, ${ }^{16,17}$ particularly as age increases, compared with WT littermates. When FoxN1 was reduced by $\sim 30 \%$ compared to its WT levels in the postnatal thymus, thymic atrophy was significantly induced. ${ }^{11,18}$ On the other hand, when FoxN1 dosage was increased by infusing minuscule amounts of vector-carried FoxN1 cDNA into a naturally aged thymus, it resulted in significant thymic rejuvenation. ${ }^{12}$ Using a Keratin(K) 14 promoter-driven FoxN1 transgenic $(\mathrm{Tg})$ mouse model the overexpression of FoxN1-attenuated age-associated thymic involution. ${ }^{14}$ Upregulating FoxN1 specifically in TECs (via inducible FoxN1ER Tg) in the aged fully involuted thymus confirmed the effect of reversing the involution. ${ }^{15}$ These experiments demonstrated that age-related thymic involution is causally associated with the loss of FoxN1. ${ }^{12,19}$ However, whether the dosage of FoxN1 can be regarded as 'the more, the better' for promoting thymic development is arguable. In addition, another recent report using the same K14-FoxN1 transgenic mice showed that FoxN1 expressed in the bone

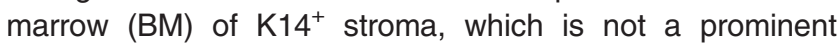
site of FoxN1 expression, promoted T-lineage production, but

\footnotetext{
${ }^{1}$ Zhejiang Provincial Key Laboratory of Aging and Neurological Disorder Research, First Affiliated Hospital, Wenzhou Medical University, Wenzhou, China and ${ }^{2}$ Department of Cell Biology and Immunology, University of North Texas Health Science Center at Fort Worth, Fort Worth, TX, USA

${ }^{*}$ Corresponding author: Q Zhuge, Zhejiang Provincial Key Laboratory of Aging and Neurological Disorder Research, First Affiliated Hospital, Wenzhou Medical University, Wenzhou 325000, China. Tel: +86 577 88069618; Fax: +86 577 88069617; E-mail: zhugeqichuan@ vip.163.com

or D-M Su, Department of Cell Biology and Immunology, University of North Texas Health Center at Fort Worth, 3500 Camp Bowie Boulevard, Fort Worth, TX 76107, USA. Tel: +817 735 5186; Fax: +817 735 2118; E-mail: dongm2011@gmail.com

${ }^{3}$ These authors contributed equally to this work.

Abbreviations: BM, bone marrow; cTEC/mTEC, cortical/medullary thymic epithelial cells; fx, loxP-floxed-FoxN1; K14 or K5, keratin-14 or keratin-5; uCreER ${ }^{\top}$, ubiquitous promoter-driven Cre-recombinase and estrogen-receptor fusion protein; WT, wild type

Received 21.8.14; revised 31.8.14; accepted 05.9.14; Edited by G Raschellà
} 
inhibited B-lineage production. ${ }^{20}$ Therefore, another question about the role of FoxN1 in nonprominent locations arises.

We addressed these questions using an inducible FoxN1 expression mouse model-the Rosa26-STOP flox_FoxN1 transgenic mouse. ${ }^{1}$ In this mouse, the FoxN1 cDNA is driven by the ubiquitously expressed Rosa26 promoter, and its expression is enhanced by a composite of CMV immediateearly gene enhancer/chicken $\beta$-actin promoter (pCAG). ${ }^{21-23}$ This induces overexpression of exogenous FoxN1 after Cremediated deletion of the roadblock STOP flox. We found that FoxN1 over- and ectopic-expression (or nonprominent location expression) in early life stages adversely affected the development of the skin, thymus and T cells, as well as B cells, whereas $\mathrm{K} 5 \mathrm{CreER}{ }^{\top}$-mediated FoxN1 overexpression in adult mice did not cause any observable defects, and can probably be expected to attenuate age-related thymic involution as reported. ${ }^{14,15}$ Therefore, FoxN1 exhibits both temporal and tissue-specific activity.

\section{Results}

The characteristics of Rosa26-STOPflox_FoxN1 mouse model. We generated an inducible exogenous FoxN1 expression mouse model, the Rosa26-STOP flox_FoxN1 transgenic mouse, to study the biological significance of over- and ectopic-expression of FoxN1. ${ }^{1}$ In this mouse, the flag-FoxN1 cDNA (kindly provided by Dr. Brissette) ${ }^{24}$ driven by a pCAG promoter ${ }^{21-23}$ (kindly provided by Dr. McMahon) was inserted into the Rosa26 locus. This fragment was bookended by a STOP flox roadblock cassette and IRES-GFP reporter gene, respectively (Supplementary Figure S1A). The DNA construct was verified by sequencing. This makes conditional expression of the FoxN1 transgene controlled by tissue-specific Cre/CreER ${ }^{\top}$ genes. We first selected K14Cre to mediate the removal of the roadblock, because $\mathrm{K} 14^{+}$ epithelial cells are epithelial progenitor cells in the skin, lung, and breast epithelial basal layer, and FoxN1 is a regulator that controls skin and thymic epithelial progenitor cell differentiation. We found that newborn mice with both Rosa26-STOPflox_FoxN1 and K14Cre transgenes (termed

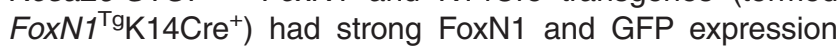
(Supplementary Figures S1B and C) in the skin and thymus. ${ }^{1}$ To verify the targeted locus, Southern blot for Rosa26STOP flox_FoxN1 mouse genomic DNA was performed. The results of correct genomic DNA size (with EcoRV digestion) are shown in Supplementary Figure S1D. To verify whether this exogenous FoxN1 is functional, we crossbred the Rosa26-STOP flox_FoxN1 mice with FoxN $1^{\text {flox }}-\mathrm{K}_{5} \mathrm{CreER}^{\mathrm{T}}$ conditional gene knockout (cKO) mice ${ }^{11}$ to get FoxN1 $1^{T g}$. FoxN $1^{\text {flox }}$ cKO mice. In this mouse, tamoxifen (TM) induction via K5CreER ${ }^{T 25}$ conditionally knocks out endogenous FoxN1 while inducing exogenous FoxN1 expression. We found that the FoxN1 $1^{\mathrm{Tg}}$-Fox $N 1^{\text {flox }}$ cKO mice had a normal thymus (data not shown), whereas FoxN $1^{\text {flox }}$ cKO mice alone had an atrophied thymus, ${ }^{11}$ indicating FoxN $1^{\mathrm{Tg}}$ has normal FoxN1 activity that can compensate for the loss of FoxN1 flox $^{\text {in the }}$ thymus.

Unfortunately, FoxN1 ${ }^{T g} \mathrm{~K} 14 \mathrm{Cre}^{+}$mice cannot survive for more than $24 \mathrm{~h}$ after birth. The mice had opened eyes from later gestation until birth compared to their FoxN1 ${ }^{\text {Tg }} \mathrm{K}_{14} \mathrm{Cre}^{-}$(nonexogenous FoxN1 expression) littermates (Supplementary Figure S1E).

Neonatal FoxN1 ${ }^{\mathrm{Tg}} \mathrm{K} 14 \mathrm{Cre}^{+}$mice had increased skin permeability and defect in nursing. In order to determine what causes FoxN $1^{\mathrm{Tg}} \mathrm{K} 14 \mathrm{Cre}{ }^{+}$neonatal death, we focused on water intake and retention, because our neonatal mice share similar phenotypes with the involucrin promoterdriven FoxN1 transgenic neonatal mice, ${ }^{24}$ which possess open eyes at birth and neonatal lethal phenotype with dehydration. Using an D-galactopyranoside (X-gal) staining approach, which is one of the skin barrier function assays used for determining skin permeability, ${ }^{26}$ we found that FoxN $1^{\mathrm{Tg}} \mathrm{K} 14 \mathrm{Cre}{ }^{+}$newborn skin permeability was increased, mostly focused around the eye region (arrows in Figure 1a). The increased region of skin permeability was consistent with the open-eye phenotype. We also found that these newborn mice cannot nurse by checking their stomach (Figure 1b). In addition, the microstructure of FoxN1 ${ }^{\mathrm{Tg}} \mathrm{K}_{14 \mathrm{Cre}}{ }^{+}$newborn skin showed increased thickness in the epidermal layer (blue arrow in Figure 1c) and flattened structure in the muscle layer (red arrow in Figure 1c), which are related to dehydration and flexibility in the stratum corneum. ${ }^{27}$ The structure looks similar to the changes seen in congenital ichthyosis, ${ }^{27}$ but not as severe. These phenotypes suggest that FoxN1 overexpression in $\mathrm{K}_{14}{ }^{+}$epithelium of the skin induces developmental mutations that result in an increase in skin permeability and defect in nursing. Therefore, FoxN $1^{\mathrm{Tg}} \mathrm{K} 14 \mathrm{Cre}{ }^{+}$neonates die from dehydration.

Overexpression of exogenous FoxN1Tg, mediated by uCreER ${ }^{\mathbf{T}}$ in juveniles, adversely affects thymus juvenile stage maturation. We next asked whether FoxN1 overexpression influences thymus development and T lymphopoiesis, as the main role of FoxN1 is the regulation of TEC development, thereby ensuring thymus and $\mathrm{T}$ cell development. We observed thymic microstructure and thymocyte profile of FoxN1 ${ }^{\mathrm{Tg}} \mathrm{K} 14 \mathrm{Cre}{ }^{+}$neonatal mice (Supplementary Figure S2), but did not find any differences compared to their FoxN1 ${ }^{\mathrm{Tg}} \mathrm{K} 14 \mathrm{Cre}{ }^{-}$littermate controls. Upon crossbreeding Rosa26-STOP flox_FoxN1 mice with uCreER ${ }^{\top}$ mice, ${ }^{11,28}$ the neonates exhibited the same features as that of the FoxN1 ${ }^{\mathrm{Tg}} \mathrm{K} 14 \mathrm{Cre}^{+}$neonates: a normal thymic microstructure and thymocyte profile, but the FoxN1 $1^{\mathrm{Tg}} \mathrm{UCreER}{ }^{\mathrm{T}+}$ neonatal mice did not have a lethal phenotype. However, FoxN1 $1^{T g} \mathrm{u}-$ CreER $^{T+}$ mice cannot survive for more than 3 weeks following birth. Furthermore, thymic and thymocyte phenotypes underwent dramatic changes $\sim 20$ days after birth, likely as a result of the progressive expression of exogenous FoxN1 $1^{\mathrm{Tg}}$ in the juvenile stage, mediated by a progressive leakage of Cre-recombinase from $u C r e E R^{\top}$ due to incomplete ER blockage in vivo with age, which was confirmed in our previous publications $s^{1,12}$ and by an other group. ${ }^{29}$

Evidence has shown that the thymus, particularly the thymic medulla, continuously undergoes maturation in the juvenile stage. ${ }^{30}$ We found that ubiquitous FoxN1 overexpression in the juveniles indeed promoted a thymic medulla-skewed maturation, which resulted in an infusion of thymic medullary 
a

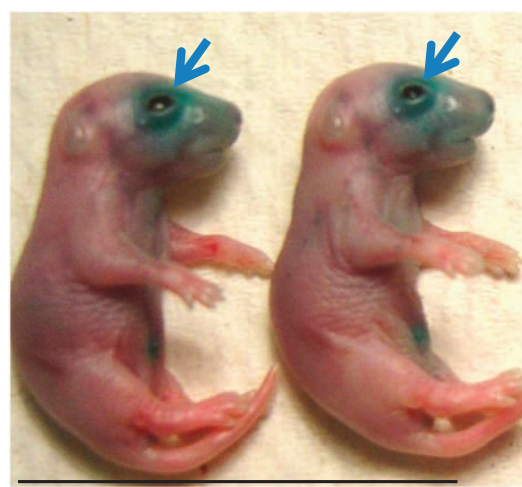

FoxN1 ${ }^{\text {Tg }} \mathrm{K} 14 \mathrm{Cre}^{+}$

b

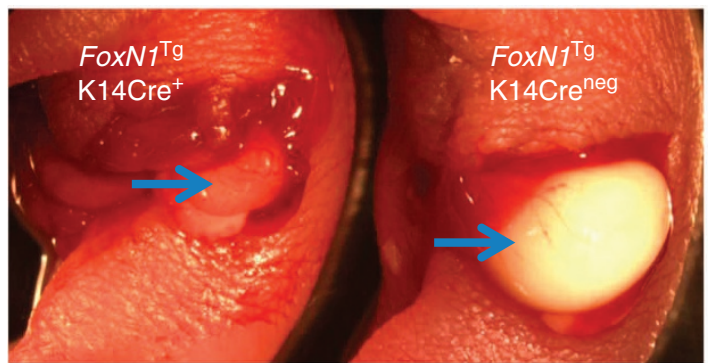

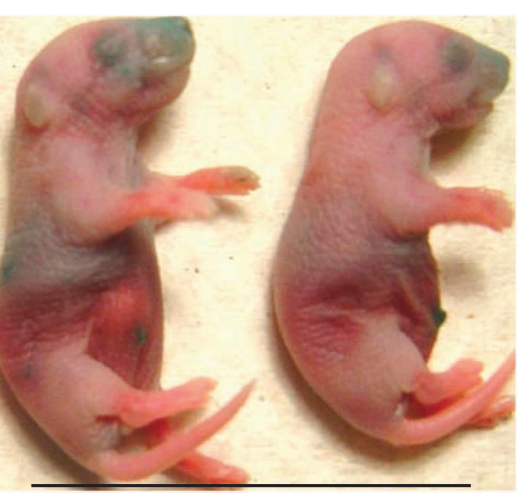

FoxN1'Tg 14 Cre ${ }^{\text {neg }}$

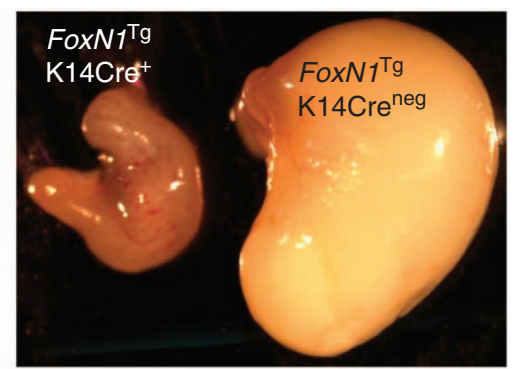

C

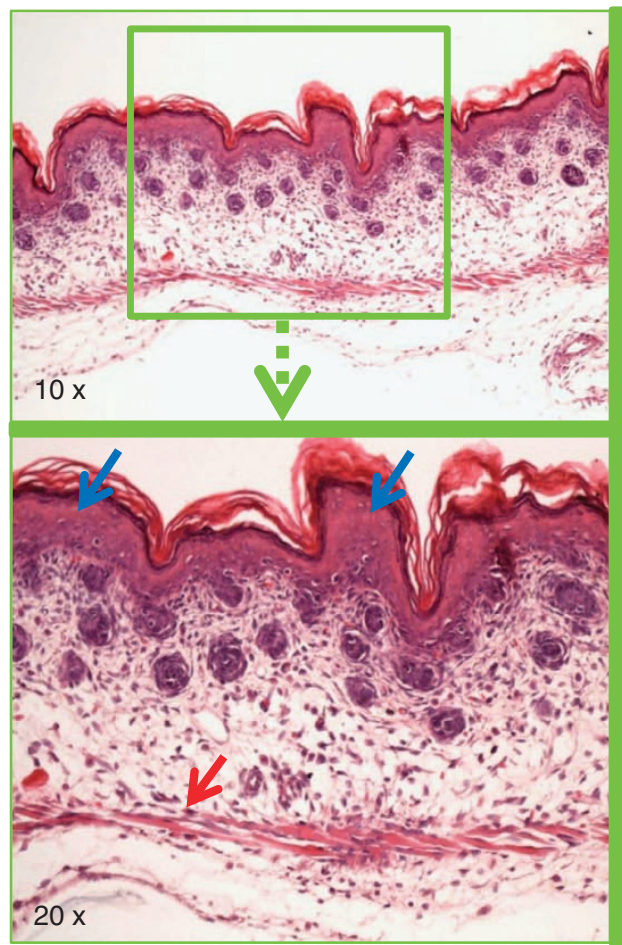

FoxN1 ${ }^{\mathrm{Tg}} \mathrm{K} 14 \mathrm{Cre}^{+}$

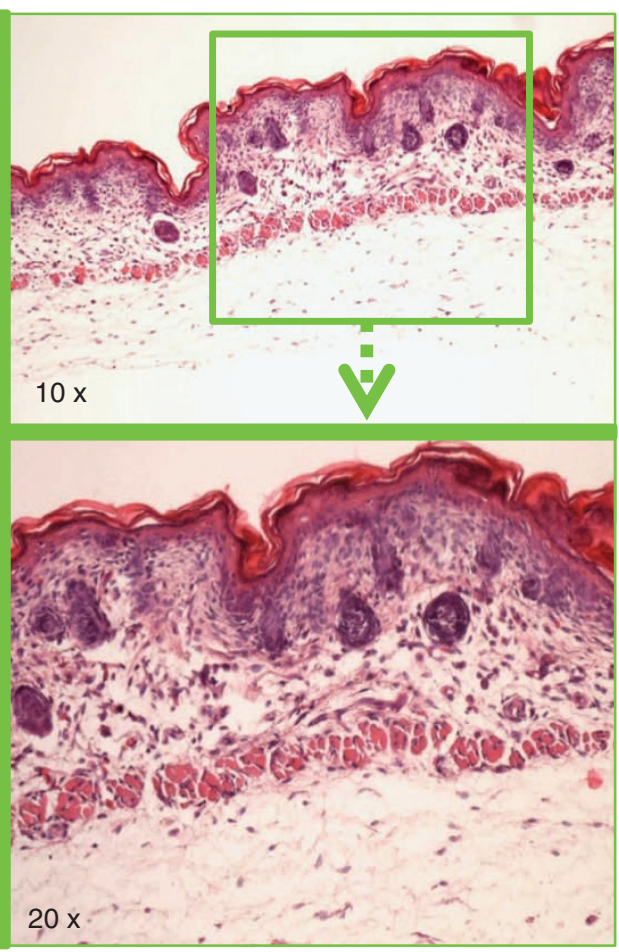

FoxN1 ${ }^{\text {Tg }} \mathrm{K} 14 \mathrm{Cre}{ }^{\text {neg }}$

Figure 1 FoxN1 overexpression mediated by $\mathrm{K} 14 \mathrm{Cre}^{+}$-induced defects in skin and nursing in newborn mice. (a) Skin permeability assay with X-gal shows increased permeability, mostly focused around the eyes (blue arrows) of FoxN1 ${ }^{\top 9} \mathrm{~K} 14 \mathrm{Cre}{ }^{+}$newborn mice; (b) stomachs (blue arrows) of FoxN1 ${ }^{\top 9} \mathrm{~K} 14 \mathrm{Cre}{ }^{+}$(left) and FoxN1 ${ }^{\top} \mathrm{K} 14 \mathrm{Cre}{ }^{-}$(right) newborn mice, with little to no milk in the stomach of $\mathrm{FoxN1}^{\top \mathrm{Tg}} \mathrm{K} 14 \mathrm{Cre} \mathrm{e}^{+}$newborn mouse; and (c) skin histological assay (H\&E staining) shows increased thickness in the epidermal layer (blue arrow) and flattening in the muscle layer (red arrow) of FoxN1 $1^{\mathrm{Tg}} \mathrm{K} 14 \mathrm{Cre}{ }^{+}$newborn mice 

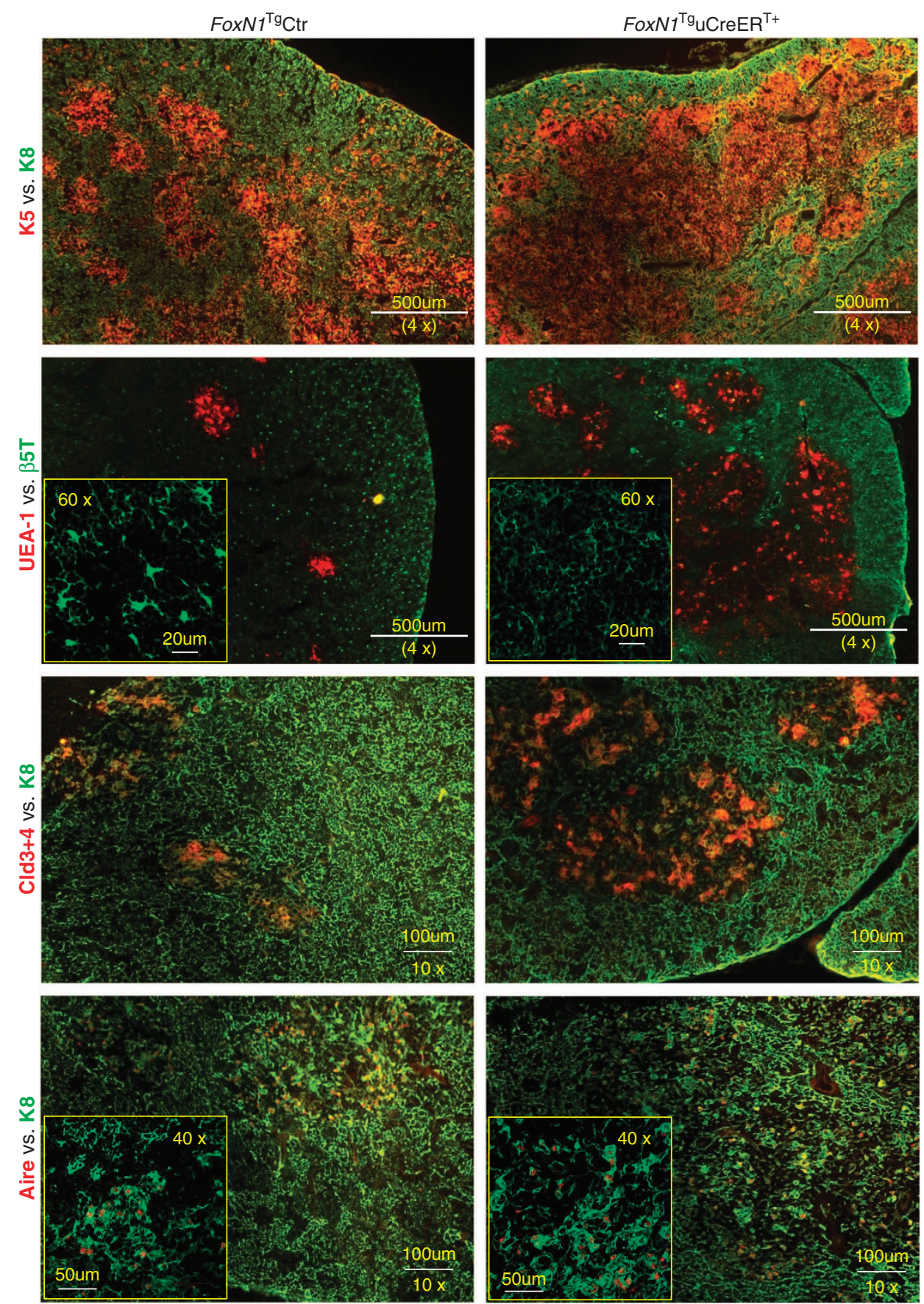

Figure 2 Overexpression of FoxN1 mediated by $\mathrm{uCreER}^{T_{+}}$in juvenile mice induced medullary-biased abnormality of thymic microstructure. Representative immunofluorescence staining shows the thymuses of FoxN1 ${ }^{\top \mathrm{T}} \mathrm{uCreER}{ }^{\mathrm{T}+}$ juvenile ( 20 days after birth) mice (right panels) had infused thymic medullary islets (top panels), an increase in UEA $-1^{+}$and Cld $3,4^{+}$TECs (panels in middle two rows), an increase in Aire ${ }^{+}$mTECs (bottom panels), and dimness of $5 \beta t^{+}$bright dendritic-shaped spots (second row from top), compared to their normal littermate controls (left panels). This experiment was repeated three times with at least three animals in each group producing consistent results

islets to occupy a large region (Figure 2, top panels), and increased the proportion of claudin-3, $-4\left(\mathrm{Cld} 3,4^{+}\right)$and UEA-1 ${ }^{+}$ TECs (Figure 2 middle rows), which represent immature $(\mathrm{Cld} 3,4)^{31}$ and mature organized mTECs (UEA-1), ${ }^{32}$ respectively, as well as an increase in Aire ${ }^{+}$mTECs (Figure 2 bottom panels). However, the trade-off for enhanced mTEC maturation was defective cTECs, as exhibited by diminished $\beta 5 \mathrm{t}^{+}$dendritic-shaped bright spots that are normally observed in the FoxN1 ${ }^{\mathrm{Tg}} \mathrm{uCreER}{ }^{-}$control thymus (Figure 2, left panel in the second row). $\beta 5$ t is considered a cTEC biomarker ${ }^{33}$ and is essential for the positive selection of T cell receptor. ${ }^{34,35}$ Flow cytometry analysis of the ratio of mTECs/cTECs further 
a

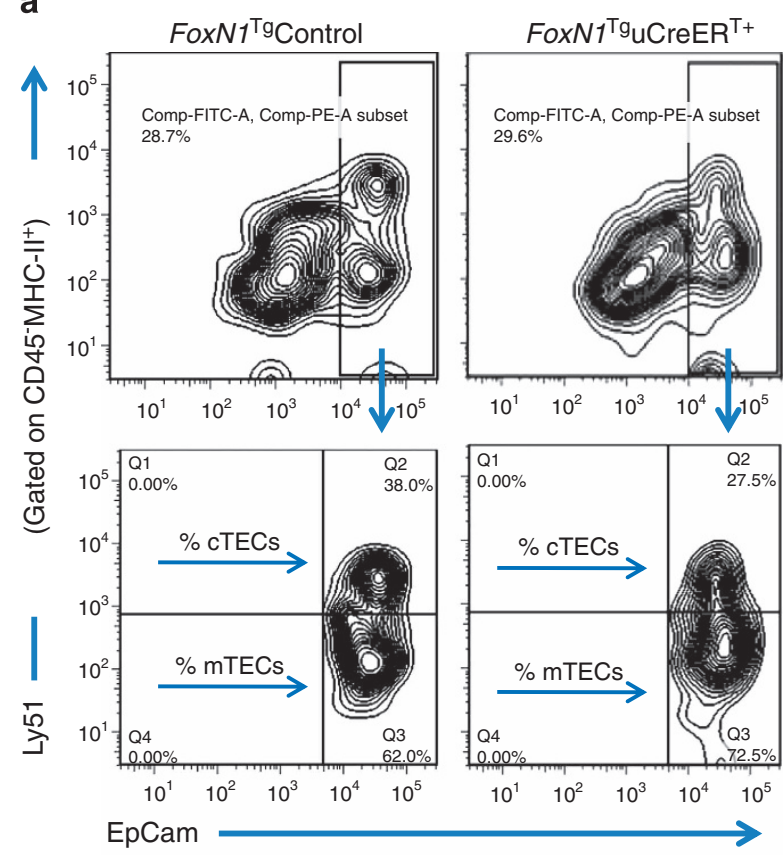

b

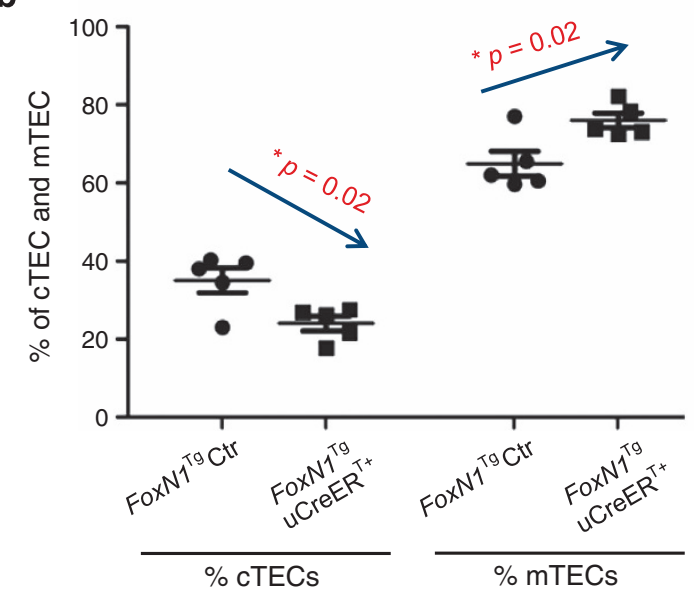

Figure 3 Ratio of mTEC/cTEC with flow cytometry assay confirms medullarybiased development in FoxN1 ${ }^{\mathrm{Tg}} \mathrm{UCreER}{ }^{\mathrm{T}+}$ juvenile mice. (a) Contour plots show representative flow cytometric gates of MTEC and CTEC subpopulation; and (b) summarized result from five mice in each group shows decreased percentages of cTECs and increased percentages of mTECs in FoxN1 ${ }^{T g} \mathrm{UCreER}^{\mathrm{T}+}$ juvenile ( 20 days after birth) mice. ${ }^{*}=$ statistically significant

confirmed that the proportion of mTECs were increased at the expense of cTECs (Figure 3 ).

On checking the thymocyte profile, we found that the thymic size (Figure 4a) and weight (Figure 4b) were reduced in the FoxN1 overexpression group. Furthermore, the thymocyte profile was obviously changed compared with control group (Figure 4c), with significantly decreased absolute cell number of total thymocytes (Figure $4 d$ ) and all subpopulations (Figure $4 \mathrm{e}$ ), especially $\mathrm{CD}^{+} 8^{+}$double positive cells. The results indicate that FoxN1 overexpression in juvenile mice adversely affected thymocyte development by influencing thymic microstructure maturation and potential ectopic expression of FoxN1 in hematopoietic cells via $\mathrm{uCreER}^{\top}$ mediation.

Fox $N 1^{\mathrm{Tg}} \mathrm{UCreER}^{\mathrm{T+}}$ juveniles showed deterioration of $\mathrm{T}$ cell function in the periphery. We asked whether reduced thymocyte number, resulting from the overexpression of exogenous FoxN1, affects mature $T$ cell function in the periphery by testing CD4 splenic $T$ cell responsiveness to anti-CD3 $\varepsilon$ and anti-CD28 costimulation. We noticed that the proportion of splenic $T$ cells were significantly increased (Figures $5 \mathrm{a}$ and b), whereas the absolute cell number was significantly decreased (Figure 5c). IL-2 production was significantly decreased in $\mathrm{CD}^{+}$splenic $\mathrm{T}$ cells in response to costimulation (Figure $5 \mathrm{~d}$ ), implying that the peripheral $\mathrm{T}$ cells were functionally impaired in the FoxN1 $1^{\mathrm{Tg}} \mathrm{uCreER}^{\mathrm{T}+}$ juvenile mice.

Ectopic expression of exogenous $\mathrm{FoxN1} 1^{\mathrm{Tg}}$, mediated by uCreER $^{\top}$ in juvenile BM, adversely affects $B$ cell development. We noticed that the FoxN $1^{T g} \mathrm{uCreER}^{\mathrm{T}+}$ juvenile mice had dramatically reduced mass of both the thymus and spleen, and absolute total cell number in both the thymus and spleen (Figure 4a). We also noticed that with the increased proportion of $\mathrm{T}$ cells in the spleen (Figure $5 \mathrm{a}$ ), the proportion of $B$ cells (Figure $6 a$, top panels) and absolute B cell number (data not shown) in the spleen were significantly decreased. This led us to determine whether defects in B cell development were due to ectopic expression of $F o x N 1^{\mathrm{Tg}}$ mediated by $\mathrm{uCreER}^{\mathrm{T}}$, which should ubiquitously induce FoxN1 $1^{\mathrm{Tg}}$ expression in a wide range of tissues ${ }^{28}$ including hematopoietic cells. We analyzed B cells in the BM, which is the site for B cell development, and found that the proportion of $B$ cells in the BM was indeed decreased (Figure 6a, bottom panels).

In order to confirm the expression of FoxN1 in the BM of FoxN1 $1^{\mathrm{Tg}} \mathrm{uCreER} \mathrm{R}^{\mathrm{T}+}$ mice, we checked FoxN1 mRNA level with real-time RT-PCR. We flushed and collected total BM from femurs, depleted red blood cells, then isolated total mRNA with TRIzol reagent, and digested any transgenic DNA contamination via DNase-I enzymatic treatment. Because transgenic FoxN1 cDNA is characterized by the absence of introns in the genomic DNA sequence, PCR products generated using intron-spanning primers cannot differentiate the transgenic cDNA, which is already incorporated into the genomic DNA of the transgenic mice. Therefore, complete removal of DNA with DNase-I before reverse transcription is critical. We determined that FoxN1 was markedly expressed in the BM of $\mathrm{FoxN}^{\mathrm{Tg}} \mathrm{u}$ $\mathrm{CreER}^{\mathrm{T}+}$ juvenile mice (Figure $6 \mathrm{~b}$ the rightmost bar). However we did not detect FoxN1 expression in the BM of WT control mice, by comparing the WT spleen, which should not have any FoxN1 expression (Figure 6b). The results indicate that FoxN1 ${ }^{\mathrm{Tg}} \mathrm{uCreER^{T+ }}$ mice have ectopic FoxN1 expression in the BM following the deletion of STOP $P^{\text {flox }}$, mediated by uCreER ${ }^{\top}$.

Overexpression of exogenous $\mathrm{FoxN1} 1^{\mathrm{Tg}}$, mediated by $\mathrm{K} \mathrm{CreER}^{\mathbf{T}}$, has different effects in adult and juvenile mice. As K5 is a partner of K14 with the same localization and similar characteristics, ${ }^{36,37}$ we crossbred Rosa26STOP flox_FoxN1 mice with K5CreER ${ }^{\top}$ mice, ${ }^{25}$ which express $\mathrm{K} 5$-deriven Cre-recombinase upon TM induction. We did not 
a

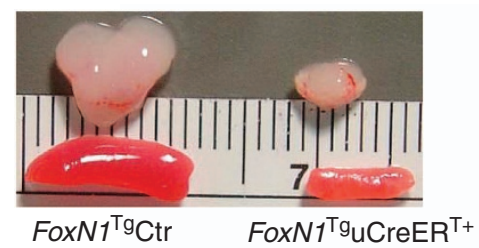

C

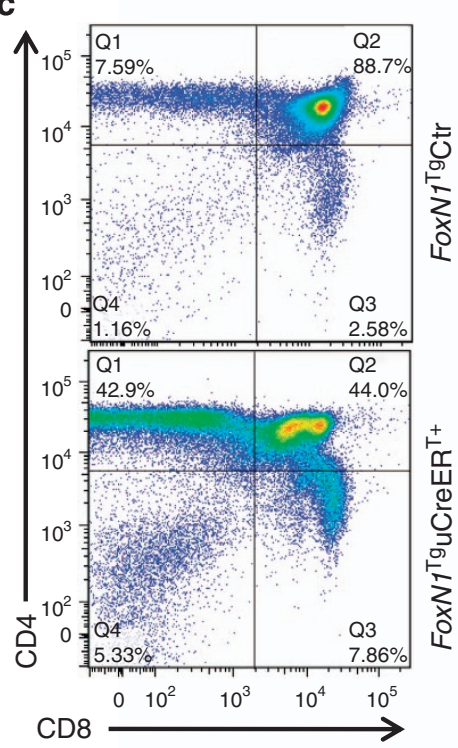

b
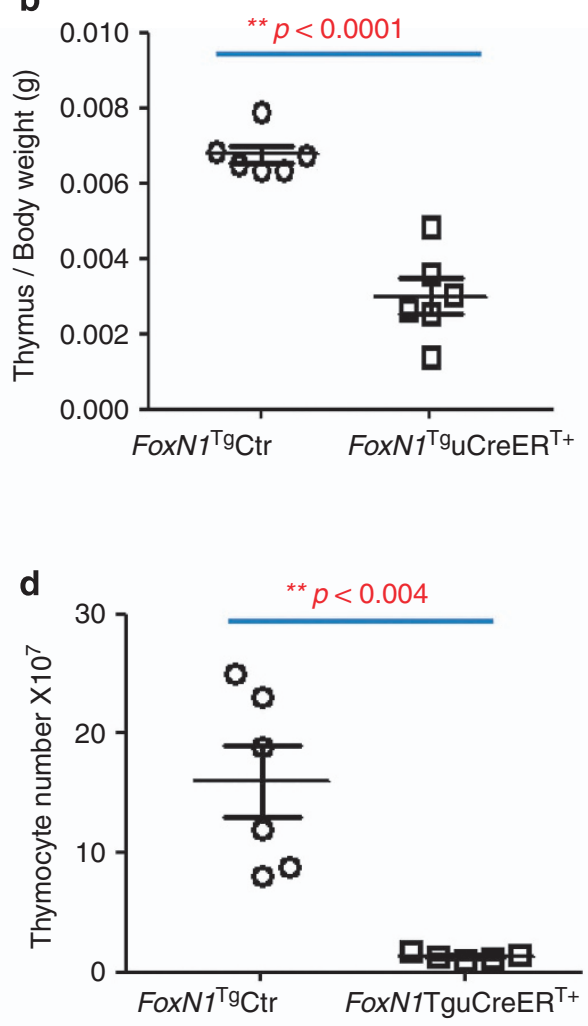

e

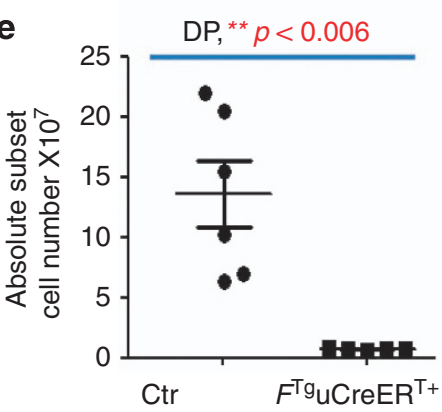

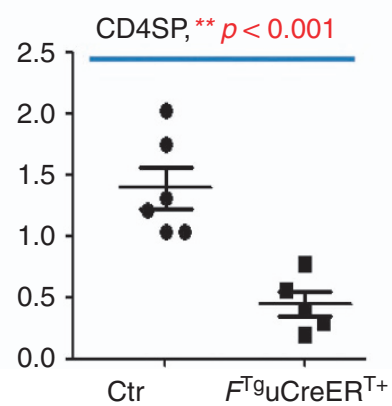

CD8SP, ${ }^{* *} p<0.002$

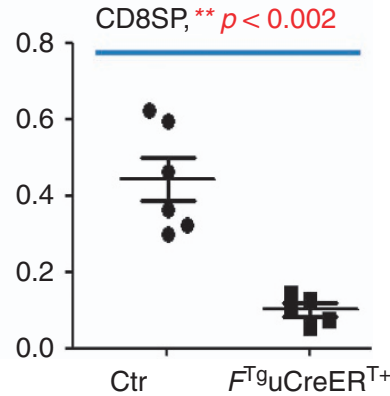

Figure 4 uCreER ${ }^{T+}$-mediated FoxN1 overexpression reduced the thymus and spleen, and cell numbers, altered thymocyte profile. (a) A representative image of the thymus and spleen of FoxN1 ${ }^{T g} \mathrm{UCreER}{ }^{\mathrm{T}+}$ juvenile ( 20 days after birth) mice and their littermate controls; (b) the thymus/body weight from seven randomly selected animals in each group; (c) a representative CD4 versus CD8 profile with flow cytometry assay; (d) absolute total thymocyte number; and (e) absolute CD4 $4^{+}$DP, $C D 4 S P$, and CD8SP thymocyte numbers (each spot represents one animal). ${ }^{* *}=$ statistically very significant

observed postnatal FoxN1 gain-of-function mutation-induced newborn lethal phenotype, and the mice have a normal lifespan.

We found, by observing GFP expression in juvenile (2 weeks) thymuses, that Cre-recombinase leakage in $\mathrm{K}_{5} \mathrm{CreER}^{\top}$ was not as strong as in $\mathrm{uCreER}^{\top}$ (Supplementary Fig. S3). Therefore, we intraperitoneally injected TM into these mice to enhance induction of FoxN1 $1^{\mathrm{Tg}}$ expression in Fox $N 1^{\mathrm{Tg}} \mathrm{K}_{5}$ CreER ${ }^{\mathrm{T}+}$ newborn and adult (4-5 weeks) mice (described in Figure 7a). In adult mice we found that following five-time $(5 \times)$ TM-injections, the FoxN1 $1^{\mathrm{Tg}}$ did not result in any adverse phenotypes in the skin and thymus (mass, total thymocyte number, and CD4 versus CD8 profile, Figure 7b). However, in juvenile mice, after $\times 4$ TM-injections at the neonatal stage, mild adverse phenotypes were observed in the juvenile thymus, such as reduced thymic mass, total thymocytes, and all subset cell numbers (data not shown), but there was no change in CD4 versus CD8 profile (Figure 7c). However, this induction strategy induced a severe skin phenotype, exhibiting ichthyosis-like coarse skin and hair loss phenotypes (Figures $7 d$ and e). The results suggest that: (1) FoxN1 $1^{\mathrm{Tg}}$ overexpression in the juvenile stage may adversely influence the underdeveloping epithelium, whereas it may not affect or may even be beneficial for mature epithelial tissues in adults: ${ }^{15}$ (2) this adverse effect is more severe in the skin than in the thymus.

\section{Discussion}

The biological significance of inborn and postnatal loss-offunction mutations in the FoxN1 gene has been studied for 
a

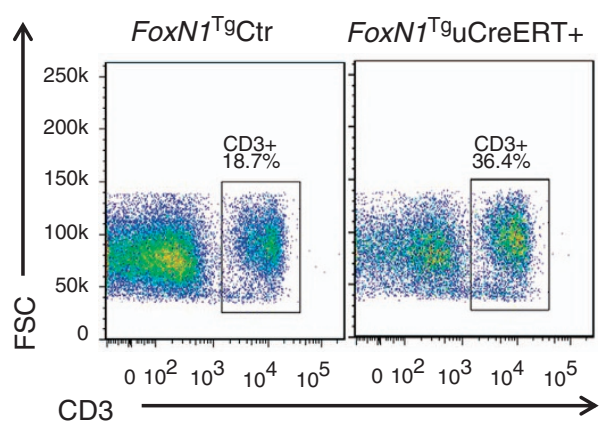

b

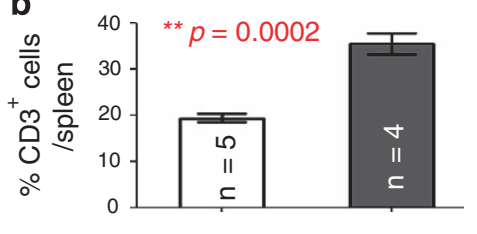

c

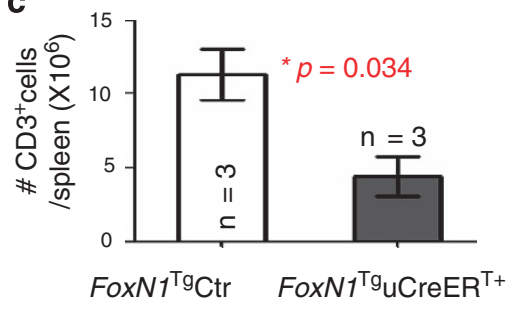

d
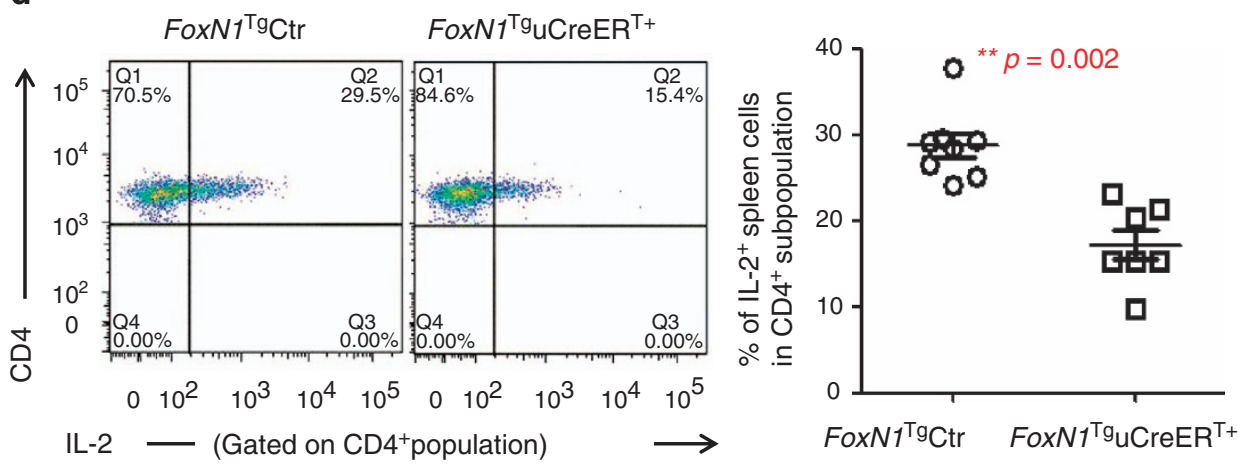

Figure $5 \mathrm{~T}$ cells in FoxN1 ${ }^{\mathrm{Tg}} \mathrm{uCreER}{ }^{\mathrm{T}+}$ juvenile mice increased \%, reduced absolute number, and declined responsiveness. (a) Representative flow cytometric gates of splenic $\mathrm{CD}^{+} \mathrm{T}$ cells; (b) summarized results of the percentages of $\mathrm{CD}^{+} \mathrm{T}$ cells in the spleen; (c) summarized results of absolute $\mathrm{CD} 3^{+} \mathrm{T}$ cell number per spleen $(n=$ number of animals in panels $\mathrm{B}$ and $\mathrm{C}$ ); and (d) dot plots on the left show a representative flow cytometric experiment of splenic IL-2 ${ }^{+} \mathrm{T}$ cells in $\mathrm{CD} 4^{+}$population gate in response to costimulation from anti-CD3 $\varepsilon$ and anti-CD28, whereas the panel on the right shows summary of CD4 ${ }^{+} \mathrm{IL}-2^{+} \mathrm{T}$ cells in the spleen in response to costimulation from anti-CD3 $\varepsilon$ and anti-CD28 (seven animals in each group). ${ }^{*}=$ statistically significant; ${ }^{* *}=$ statistically very significant

several decades. ${ }^{4,8-11,38,39}$ However, the biological significance of inborn and postnatal FoxN1 gain-of-function mutations has just begun to be probed. ${ }^{12,14,15,20,24}$ In this report, we used our newly developed inducible tissue-specific mouse model for FoxN1 gain-of-function mutations to establish biologically significant evidence that over- and ectopicexpression of FoxN1 in early life influences immature TEC, $\mathrm{T}$ and $\mathrm{B}$ cell, and skin epithelial development. We found that K14Cre-mediated Rosa26-STOP flox_FoxN1 ${ }^{\text {Tg }}$ newborns had a neonatal lethal phenotype caused by dehydration due to abnormal permeability in the skin and defect in nursing. These neonatal mice shared similar phenotypes with the involucrin promoter-driven FoxN1 transgenic neonatal mice, ${ }^{24}$ which have enhanced ectopic expression of FoxN1. The uCreER ${ }^{\top}$ mediated overexpressed FoxN1 induced by progressive leakage of Cre-recombinase beyond the neonatal stage affected the development of the thymus, thymocytes, and $\mathrm{BM}$ in the juvenile stage, indicating that TEC development skewed towards mTECs, thymocyte numbers were significantly decreased in all subsets, a proportion of peripheral $T$ cells was increased but the absolute number and functional response were significantly reduced, and the numbers of BM and peripheral $B$ cells were significantly decreased. However, K5CreER ${ }^{\top}$-mediated FoxN1 overexpression via TM induction in the adults resulted in normal thymus and skin, whereas mice subjected to TM induction as neonates had mildly abnormal development of the thymus, and severe ichthyosis-like skin in the juvenile mice.

Generally, enhancing FoxN1 expression in an aged thymus should rejuvenate atrophied dysfunction, as FoxN1 is decreased with age..$^{12,14,15,19}$ However, no reports thus far looked into whether enhanced FoxN1 expression in the juvenile thymus, which already has high levels of FoxN1, is beneficial for further thymic development. Our report provides a negative answer, in which FoxN1 gain-of-function mutations in juvenile mice (younger than 3 weeks, before weaning) had an adverse effect on thymic development. This adverse effect on the skin occurred early (neonatal stage) and was severe (lethality). Interestingly, these lethal phenotypes were not reported in $\mathrm{K} 14$ and $\mathrm{K} 5$ promoter-driven FoxN1 transgenic mice made by other groups. ${ }^{14,40}$ This is probably because we used both the Rosa26 promoter to ensure the FoxN1 gene is expressed in all Rosa26 positive tissues (almost ubiquitously), followed by pCAG promoter $^{21-23}$ to ensure strong FoxN1 expression. The pCAG promoter is a CMV-IE enhancer plus chicken $\beta$-actin promoter sequence, ${ }^{21}$ which was confirmed to be able to drive enhanced gene expression, ${ }^{41}$ particularly in the cutaneous epithelium, ${ }^{21}$ which may explain why the skin phenotype is so strong. However, upregulating FoxN1 in later life stage via inducible pCAG-FoxN1ER mediated by FoxN1- 
a

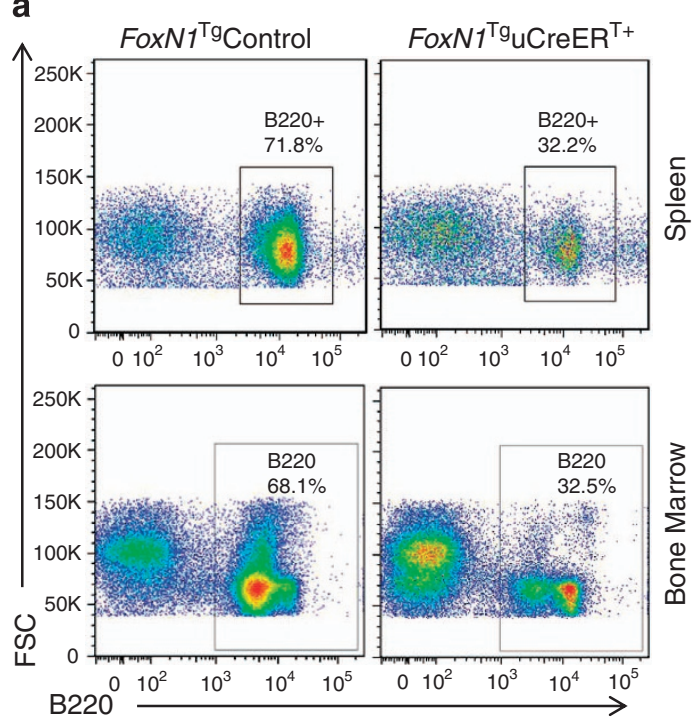

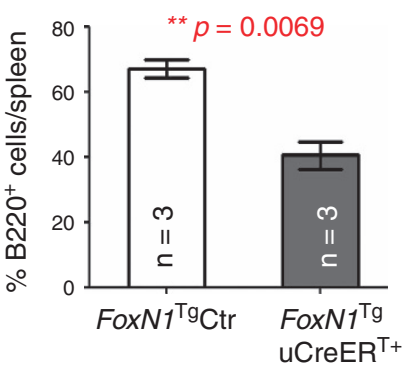

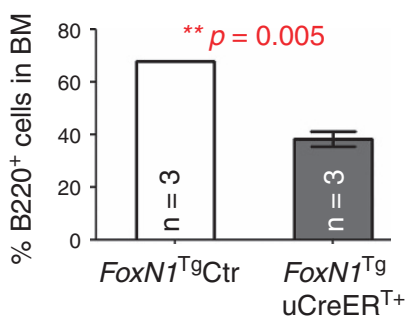

b

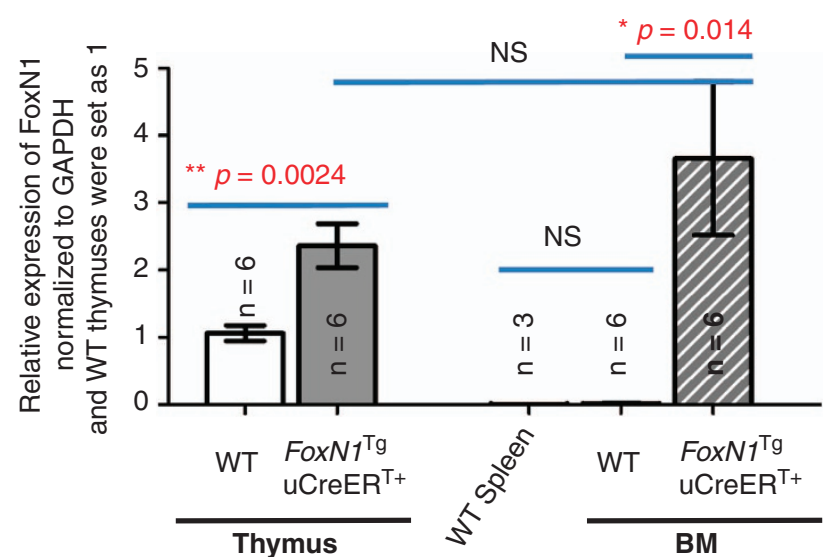

Figure 6 Defective $\mathrm{B}$ cell development in the spleen and BM of FoxN1 ${ }^{T g} \mathrm{UCreER}{ }^{\mathrm{T}+}$ juvenile mice. (a) Flow cytometric dot plots on the left show representative gates on splenic (top panels) and BM (bottom panels) B220 $\mathrm{B}$ cells, whereas the panels on the right show summarized results of the percentages of B220 $\mathrm{B}$ cells in the spleen (top bar graph) and BM (bottom bar graph; and (b) FoxN1 expression in the thymus and BM of FoxN1 ${ }^{\top g} \mathrm{uCreER}^{\mathrm{T}}$ juvenile mice tested by real-time RT-PCR assay; ( $n=$ number of animals). ${ }^{*}=$ statistically significant; ${ }^{* *}=$ statistically very significant

Cre $\mathrm{Tg}$, which achieves overexpressing exogenous FoxN1 only in endogenous FoxN1-declined TECs, is beneficial to rejuvenation of aged thymic function. ${ }^{15}$

We did not observe defects during thymic development induced by FoxN1 gain-of-function mutations in the prenatal thymus in our K14-, K5-, and ubiquitous Cre-mediated FoxN1 overexpressing mice. Therefore, the dosage of FoxN1 could be considered 'the more, the better' in the prenatal thymus. However, FoxN1 gain-of-function mutations in the early postnatal thymus resulted in defects in TEC development, as observed in the ubiquitous $\mathrm{CreER}^{\top}$ (continuous Crerecombinase leaky)-mediated and $\mathrm{K} \mathrm{CreER} \mathrm{R}^{\top}$ (juvenile mice with TM x4)-mediated Rosa26-STOP ${ }^{\text {flox }}-$ FoXN1 $1^{\text {Tg }}$ mice (Figures 2-4 and 7c). Therefore, the dosage of FoxN1 could not be considered 'the more, the better' for juvenile stage thymic development. At this stage, the thymic medulla is still undergoing development, ${ }^{30}$ and expression of FoxN1 may be just beginning to decline in the natural thymus, where enhancing FoxN1 expression may break this balance.
However, in the adult and late postnatal thymus, FoxN1 ${ }^{+}$ TECs are markedly reduced. ${ }^{42,43}$ Enhancing FoxN1 expression may produce a beneficial effect that may slow down thymic aging, ${ }^{14,15}$ or at least no harmful effects as shown in our $\mathrm{K} \mathrm{CreER}{ }^{\top}$ (with TM $\mathrm{x} 5$ induction in the adult)-mediated Rosa26-STOP ${ }^{\text {flox }}$-FoXN1 $1^{T g}$ transgenic adult mice (Figure $7 \mathrm{~b}$ ).

In our uCreER ${ }^{\top}$-mediated Rosa26-STOP ${ }^{\text {flox }}$-FoXN1 $1^{\text {Tg }}$ transgenic juvenile mice, we also found that $B$ lymphopoiesis was markedly decreased in the BM and spleen (Figure 6a). This is consistent with the finding in $\mathrm{K} 14$ promoter-driven FoxN1 transgenic mice, in which B-lineage cell numbers were significantly lower. ${ }^{20}$ It could be caused by exogenous FoxN1 expression in nonprominent locations, not only in BM mesenchymal origin stromal cells but also in hematopoietic origin cells because of ubiquitous CreER ${ }^{\top}$.

In our model, FoxN1 overexpression in the BM not only disrupted $B$ lymphopoiesis, but was also not beneficial for $T$ cell development. In the uCreER ${ }^{\top}$ leakage-mediated FoxN1 overexpression in Rosa26-STOP ${ }^{\text {flox }}$-Fox $N 1^{\text {Tg }}$ juvenile mice, 
a
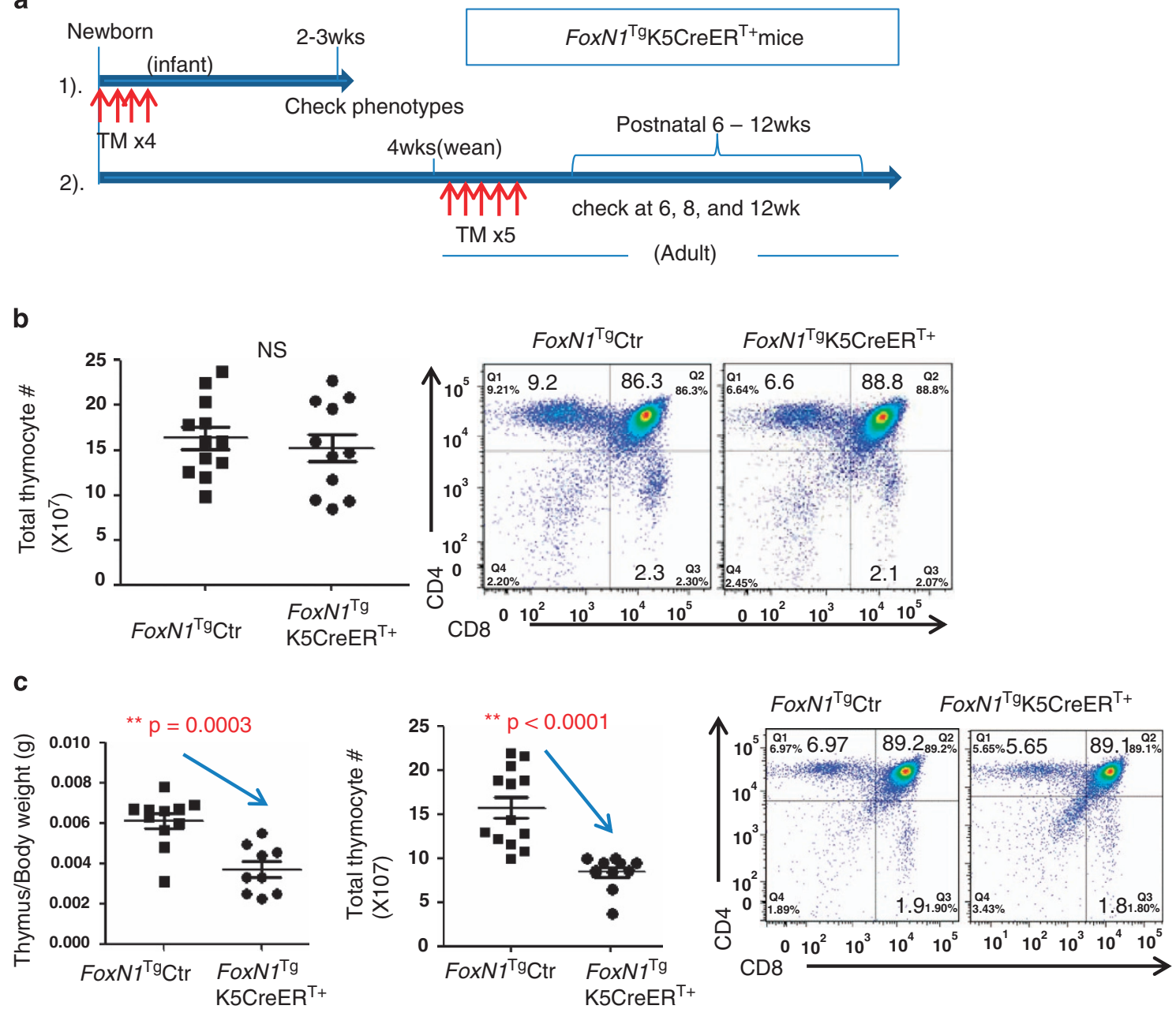

d

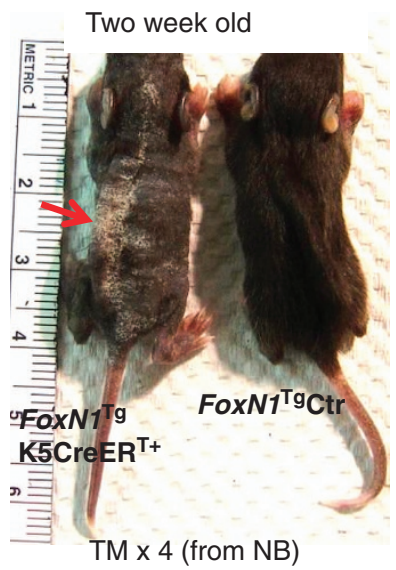

e

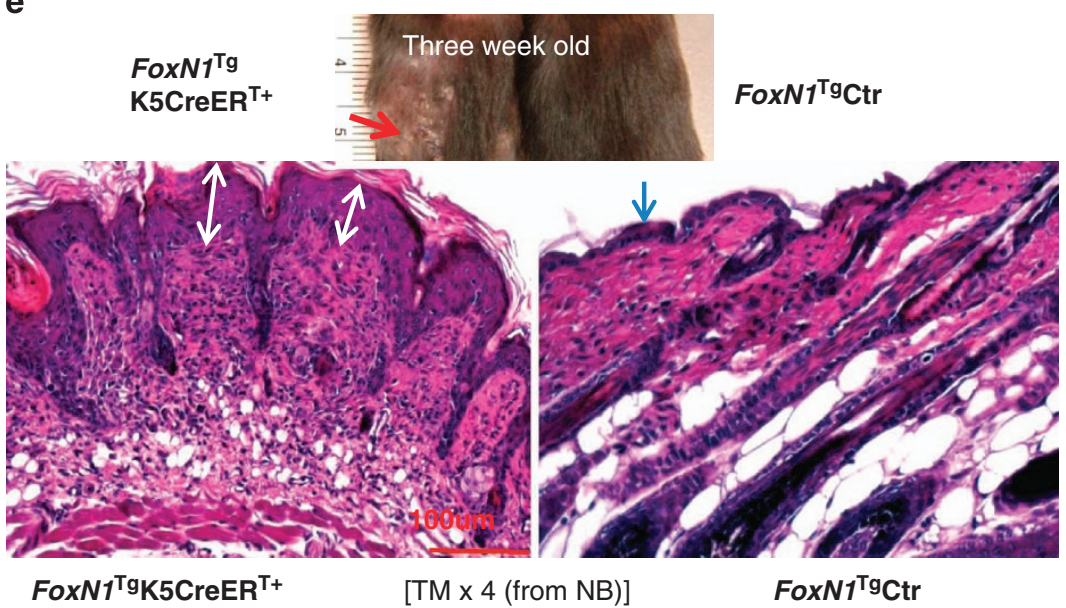

Figure 7 FoxN1 overexpression mediated by $\mathrm{K}_{5} \mathrm{CreER}^{\mathrm{T}+}$ produced different outcomes in newborn and adult thymus and skin. (a) Schematic of induced FoxN1 ${ }^{\mathrm{Tg}}$ expression with TM in FoXN1 $1^{T} \mathrm{~K}_{5} \mathrm{CreER}{ }^{\mathrm{T}+}$ newborn (strategy 1) and adult (strategy-2) mice; (b) the panel on the left shows summary of absolute total thymocyte numbers from 11 FoxN1 ${ }^{\top \mathrm{K}} \mathrm{K} 5 \mathrm{CreER}{ }^{\mathrm{T}+}$ and 11 FoxN1 ${ }^{\mathrm{Tg}} \mathrm{K} 5 \mathrm{CreER}{ }^{\top}$ - control adult mice, injected with $\mathrm{TM} \times 5$ from adult (see TM induction strategy-2, shown in panel a), whereas flow cytometric dot plots on the right show a representative profile of $\mathrm{CD} 4^{+}$versus $\mathrm{CD} 8^{+}$thymocytes; (c) the two leftmost panels show decreased thymic weight and total thymocyte numbers; the dot plots on the right show a representative profile of $\mathrm{CD} 4^{+}$versus $\mathrm{CD} 8^{+}$thymocytes in FoxN1 ${ }^{\top g} \mathrm{~K}_{\mathrm{KC}} \mathrm{CreER}{ }^{\mathrm{T}}$ juvenile mice injected with $\mathrm{TM} \times 4$ from birth (see TM induction strategy 1 , shown in panel a); (d) skin profile of FoxN1 ${ }^{T}{ }^{K} \mathrm{~K}_{5} \mathrm{CreER}{ }^{+}$2-week-old; and (e) 3-week-old juvenile mice, injected with TM $\mathrm{X} 4$ from birth (same as panel c). Image shows ichthyosislike, coarse skin and hair loss (red arrow) in a representative FoxN1 ${ }^{T}{ }_{K} 5 \mathrm{CreER}^{\mathrm{T}+}$ juvenile mouse. Panel e bottom shows representative H\&E staining of microstructure of the skin from a representative FoxN1 ${ }^{T g} K_{5}$ CreER ${ }^{T+} 3$-week-old juvenile mouse. Double headed white arrows indicate increased thickness in the epidermal layer. ${ }^{* *}=$ statistically very significant 
BM LSK (lineage negative, Sca- $1^{+}$and $\mathrm{c}-\mathrm{kit}^{+}$) cells, which are T-lymphohematopoietic progenitors in the BM, were decreased (Supplementary Figure S4) and early T-cell thymic progenitor (lineage negative, CD $44^{+} \mathrm{CD} 25^{-}$, and c-kit ${ }^{+}$) cells were increased in percentage (data not show), but decreased in absolute number along with all other thymocyte subpopulations (Figure 4). At least, FoxN1 expression in BM stromal (niche) cells is not critically required for T-cell development, as WT thymic lobes grafted into nude (FoxN1 $\left.1^{\text {null }}\right)$ mice under the kidney capsule, without any modification in the FoxN $1^{\text {null }}$ host $\mathrm{BM}$ niche, are able to generate normal T cells, which is a common model for studying lymphostromal interactions.

The FOXN1 leads to congenital alopecia and an alymphoid thymus with severe combined primary T-cell immunodeficiency, ${ }^{7,44-46}$ resulting in death in early childhood from severe infections. ${ }^{44,47}$ Therefore, gene therapy with FOXN1 is one of options to be possibly selected to treat fetal FOXN1 mutations. If so, the dosage of FOXN1, target tissues, and developmental stages must be carefully considered, because our data has demonstrated that over- and ectopic-expression of FoxN1 is pathogenic and potentially lethal. In addition, although there are not any reported diseases predicated on the over- and ectopic-expression of FoxN1, this does not rule out their discovery in the near future. A growing paradigm of microRNAs regulating gene activity is emerging. A recent report has linked silencing of microRNAs (miR-18b and miR-518b) with the upregulation of FoxN1 in embryonic stem cells. ${ }^{48}$ Evidence to support microRNA mutations affecting gene expression and leading to heritable diseases is emerging with time. Our results provide a clue of potential pathologies that could emerge from mutations in the microRNA or microRNA target regulators that maintain FoxN1 levels.

It is taken for granted that loss-of-function mutations induce defective phenotypes, whereas it is hard to accept that gain-offunction mutations can also induce defective phenotypes. Our results show that neonatal overexpression of FoxN1 mainly affects skin development, which was also demonstrated by an Involucrin promoter-driven FoxN1 transgenic mouse model. ${ }^{24}$ Our study addressed whether FoxnN1 expression in the thymus can be considered 'the more, the better'. Although it is not the case in certain developmental stages, such as in juveniles, enhancing FoxN1 expression in the FoxN1-declined aged thymus should provide significant rejuvenation. ${ }^{12,14,15}$ In fact, ectopic-expression of FoxN1 in tissues that do not predominantly express FoxN1, such as the BM, is harmful. The biological significance of gain-of-function mutations in the FoxN1 gene is summarized in Supplementary Figure S5. Ultimately, if FoxN1 is not expressed in the right tissues and right life developmental stages, then physiological abnormalities will be induced. In our models, FoxN1 gain-of-function mutations disrupted B-lymphopoiesis and did not help $\mathrm{T}$ lymphopoiesis. FoxN1 possesses developmental stage and tissue-specific activity.

\footnotetext{
Materials and Methods

Mice, age groups, genotyping, and animal care. Neonatal ( 1 day) and juvenile (2-3 weeks) mice (C57BL/6 genetic background) were used. Rosa26-STOP flox_ FoxN1 transgenic (termed FoxN1 ${ }^{\top g}$ ) mice were generated by our laboratory (available upon request), ${ }^{1}$ and genotyped with three primers (Supplementary Figure S1A). The FoXN1 ${ }^{\mathrm{Tg}}$ mice were crossbred with $\mathrm{K} 14 \mathrm{Cre},{ }^{49} \mathrm{~K} \mathrm{CreER}{ }^{\mathrm{T} 25}$ and ubiquitous pCAG-
}

CreER ${ }^{\top}$ (uCreER $\left.^{\top}\right)^{28}$ mice (Jackson Laboratories, Bar Harbor, ME, USA, \#004782, \#018394, and \#004682). The FoxN $1^{\text {flox }}$ (fx) mice carrying a TM-inducible uCreER ${ }^{\top}$ (termed fx/fx-uCreER $\mathrm{R}^{\top}$ ) were generated and genotyped as described previously ${ }^{11}$ (Jackson Laboratories \#012941). All animal experiments were performed according to the protocols approved by the Institutional Animal Care and Use Committee of the University of North Texas Health Science Center, in accordance with guidelines from the National Institutes of Health, USA.

Skin permeability assay. Details are described in a previous publication. ${ }^{26}$ In brief, freshly isolated embryos were rinsed in phosphate buffered saline (PBS) and immersed in X-gal staining reagent overnight at $30^{\circ} \mathrm{C}$. On the following day, embryos were rinsed in PBS and photographed.

IF staining. Cryosections ( $5 / 6 \mu \mathrm{m}$ thick) were stained as described previously. ${ }^{50}$ The primary antibodies used were rabbit anti-FoxN1 (provided by Dr. Itoi), ${ }^{43}$ anticlaudin-3,4 (Invitrogen, Grand Island, NY, USA, \#34-1700 and \#36-4800), antiKeratin-5 (Covance, Princeton, NJ, USA, \#PRB-160P), Biotinylated-UEA-1 (Vector Laboratories, Burlingame, CA, USA, \#B-1065), anti-Aire (Santa Cruz, Dallas, TX, USA, \#SC-33189, anti- $\beta 5$ t (Medical and Biological Laboratories, Nagoya, Japan, \#PD021), and anti-Keratin-8 (Troma-1 supernatant). The secondary antibodies used were Cy3-conjugated or Alexa-Fluor-488-conjugated donkey antirabbit or -rat IgG (Jackson ImmunoResearch Laboratories, West Grove, PA, USA).

Real-time RT-PCR. Total RNA from mouse thymus, spleen, and BM was isolated with TRIzol reagent and reverse transcribed to CDNA with the SuperScriptlll cDNA kit (Invitrogen). Real-time RT-PCR was performed with TaqMan reagents. The sequences of FoxN1 primers and probe (TaqMan method) were as described previously. ${ }^{11}$ The relative expression levels of FoxN1 mRNAs from the thymus, spleen, and BM were internally normalized to GAPDH levels, then compared with a $\Delta \Delta \mathrm{C}_{\mathrm{T}}$ value from pooled young WT thymuses. This $\Delta \Delta \mathrm{C}_{\mathrm{T}}$ value was always arbitrarily set as 1.0 in each real-time PCR reaction.

Western blot analysis. The whole thymus was subjected to homogenization and protein extraction in RIPA lysis buffer (Sigma, St. Louis, MO, USA, \#R0278). Protein, $\sim 25 \mu \mathrm{g} /$ lane, was loaded under reducing conditions for direct Western blot assay with FoxN1 ${ }^{43}$ (81 KD band) and GFP (monoclonal, Santa Cruz, \#SC-9996, 27 KD band) antibodies. GAPDH or $\beta$-actin were used as an internal loading control.

Flow cytometry assays. Single cell suspensions of thymocytes, spleen, and BM (flushed from the mouse femur) cells, as well as TECs (isolated with collagenase-V/DNase-I isolation method) ${ }^{50}$ were stained with combinations of fluorochrome-conjugated antibodies against cell surface markers and/or an intracellular marker, which are indicated in each figure. Data was acquired using a BD LSRII Flow Cytometer (BD Bioscience, San Jose, CA, USA) and analyzed using FlowJo software (Tree Star, Inc., Ashland, OR, USA).

Analysis of intracellular IL-2 in peripheral $\mathrm{CD}^{+} \mathrm{T}$ cells in response to costimulation of CD3 and CD28 antibodies. Red blood cell lysis buffer (Sigma, \#R7757) treated spleen cells $\left(2 \times 10^{6}\right.$ per well) were cultured with anti-mouse CD3 $\varepsilon$ and CD28 antibodies $(2 \mu \mathrm{g} / \mathrm{ml}$ each) supplemented with BD GolgiStop $(0.7 \mu \mathrm{l} / \mathrm{ml}$, from BD Biosciences, \#554724) for $5 \mathrm{~h}$. The harvested cells were stained for CD4 on the surface, fixed and permeabilized, ${ }^{12}$ then stained with fluorochrome-conjugated IL-2 antibody intracellularly, following flow cytometry assay.

Statistics. Statistical significance was analyzed by unpaired Student's $t$-test. Differences were considered statistically significant at values of $P<0.05$.

\section{Conflict of Interest}

The authors declare no conflict of interest.

Acknowledgements. We thank Dr. AP McMahon (USC) for kindly providing pBSAptCAGftlG vector for the generation of Rosa26-STOP ${ }^{\text {ilox }}$-FoXN1 $1^{\text {Tg }}$ mice; Dr. Zhijie Liu (UCSD) for supporting mouse generation and discussion of Rosa26STOP ${ }^{i l o x}$-FoXN1 $1^{\text {Tg }}$ mouse phenotypes; Dr. JL Brissette (SUNY Downstate Medical Center) for kindly providing FoxN1 CDNA and critically reading the manuscript; and Dr. Manami Itoi (Meiji University, Japan) for kindly providing FoxN1 antibody. 
This work was partially supported by an NIAID/NIH grant (R01Al081995) to D-MS, and by the Foundation of Zhejiang Provincial Top Key Discipline of Surgery, Nationa Natural Science Foundation of China (81371396) to QZ and National Natural Science Foundation of China (81400954) to LR.

1. Zhang Z, Burnley P, Coder B, Su DM. Insights on FoxN1 biological significance and usages of the 'nude' mouse in studies of T-lymphopoiesis. Int J Biol Sci 2012; 8: 1156-1167.

2. Pantelouris EM. Absence of thymus in a mouse mutant. Nature 1968; 217: 370-371.

3. Pantelouris EM, Hair J. Thymus dysgenesis in nude (nu nu) mice. J Embryol Exp Morphol 1970; 24: 615-623.

4. Nehls M, Kyewski B, Messerle M, Waldschutz R, Schuddekopf $K$, Smith AJ et al. Two genetically separable steps in the differentiation of thymic epithelium. Science 1996 272: 886-889.

5. Frank J, Pignata C, Panteleyev AA, Prowse DM, Baden H, Weiner $\mathrm{L}$ et al. Exposing the human nude phenotype. Nature 1999; 398: 473-474.

6. Cunningham-Rundles C, Ponda PP. Molecular defects in T- and B-cell primary immunodeficiency diseases. Nat Rev Immunol 2005; 5: 880-892.

7. Amorosi S, D'Armiento M, Calcagno G, Russo I, Adriani M, Christiano AM et al. FOXN homozygous mutation associated with anencephaly and severe neural tube defect in human athymic Nude/SCID fetus. Clin Genet 2008; 73: 380-384

8. Schlake T. The nude gene and the skin. Exp Dermatol 2001; 10: 293-304.

9. Lee D, Prowse DM, Brissette JL. Association between mouse nude gene expression and the initiation of epithelial terminal differentiation. Dev Biol 1999; 208: 362-374.

10. Mecklenburg L, Tychsen B, Paus R. Learning from nudity: lessons from the nude phenotype. Exp Dermatol 2005; 14: 797-810.

11. Cheng L, Guo J, Sun L, Fu J, Barnes PF, Metzger D et al. Postnatal tissue-specific disruption of transcription factor FoxN1 triggers acute thymic atrophy. J Biol Chem 2010; 285: 5836-5847.

12. Sun L, Guo J, Brown R, Amagai T, Zhao Y, Su DM. Declining expression of a single epithelia cell-autonomous gene accelerates age-related thymic involution. Aging Cell 2010; 9: 347-357.

13. Guo J, Feng Y, Barnes P, Huang FF, Idell S, Su DM et al. Deletion of FoxN1 in the thymic medullary epithelium reduces peripheral $T$ cell responses to infection and mimics changes of aging. PLoS One 2012; 7: e34681.

14. Zook EC, Krishack PA, Zhang S, Zeleznik-Le NJ, Firulli AB, Witte PL et al. Overexpression of Foxn1 attenuates age-associated thymic involution and prevents the expansion of peripheral CD4 memory T cells. Blood 2011; 118: 5723-5731.

15. Bredenkamp N, Nowell CS, Blackburn CC. Regeneration of the aged thymus by a single transcription factor. Development 2014; 141: 1627-1637.

16. Scheiff JM, Cordier AC, Haumont S. The thymus of Nu/+ mice. Anat Embryol (Berl) 1978; 153: $115-122$.

17. Kojima A, Saito M, Hioki K, Shimanura K, Habu S. NFS/N-nu/+mice can macroscopically be distinguished from NFS/N- +/+ littermates by their thymic size and shape. Exp Cell Biol 1984 52: $107-110$

18. Chen L, Xiao S, Manley NR. Foxn1 is required to maintain the postnatal thymic microenvironment in a dosage-sensitive manner. Blood 2009; 113: 567-574.

19. Ortman CL, Dittmar KA, Witte PL, Le PT. Molecular characterization of the mouse involuted thymus: aberrations in expression of transcription regulators in thymocyte and epithelial compartments. Int Immunol 2002; 14: 813-822.

20. Zook EC, Zhang S, Gerstein RM, Witte PL, Le PT. Enhancing T lineage production in aged mice: a novel function of foxn1 in the bone marrow niche. J Immunol 2013; 191: 5583-5593.

21. Sawicki JA, Morris RJ, Monks B, Sakai K, Miyazaki J. A composite CMV-IE enhancer/betaactin promoter is ubiquitously expressed in mouse cutaneous epithelium. Exp Cell Res 1998; 244: 367-369

22. Mao J, Barrow J, McMahon J, Vaughan J, McMahon AP. An ES cell system for rapid, spatia and temporal analysis of gene function in vitro and in vivo. Nucleic Acids Res 2005; 33: e155.

23. Yu J, McMahon AP. Reproducible and inducible knockdown of gene expression in mice. Genesis 2006: 44: 252-261.

24. Prowse DM, Lee D, Weiner L, Jiang N, Magro CM, Baden HP et al. Ectopic expression of the nude gene induces hyperproliferation and defects in differentiation: implications for the selfrenewal of cutaneous epithelia. Dev Biol 1999; 212: 54-67.

25. Indra AK, Warot X, Brocard J, Bornert JM, Xiao JH, Chambon P et al. Temporally-controlled site-specific mutagenesis in the basal layer of the epidermis: comparison of the recombinase activity of the tamoxifen-inducible Cre-ER(T) and Cre-ER(T2) recombinases. Nucleic Acids Res 1999; 27: 4324-4327.

26. Hardman MJ, Sisi P, Banbury DN, Byrne C. Patterned acquisition of skin barrier function during development. Development 1998; 125: 1541-1552.

27. Tomita Y, Akiyama M, Shimizu H. Stratum corneum hydration and flexibility are usefu parameters to indicate clinical severity of congenital ichthyosis. Exp Dermatol 2005; 14 $619-624$.
28. Hayashi S, McMahon AP. Efficient recombination in diverse tissues by a tamoxifen-inducible form of Cre: a tool for temporally regulated gene activation/inactivation in the mouse. Dev Biol 2002; 244: 305-318.

29. Matsuda T, Cepko CL. Controlled expression of transgenes introduced by in vivo electroporation. Proc Natl Acad Sci USA 2007; 104: 1027-1032.

30. Fontenot JD, Dooley JL, Farr AG, Rudensky AY. Developmental regulation of Foxp3 expression during ontogeny. J Exp Med 2005; 202: 901-906.

31. Hamazaki Y, Fujita H, Kobayashi T, Choi Y, Scott HS, Matsumoto M et al. Medullary thymic epithelial cells expressing Aire represent a unique lineage derived from cells expressing claudin. Nat Immunol 2007; 8: 304-311.

32. Farr AG, Anderson SK. Epithelial heterogeneity in the murine thymus: fucose-specific lectins bind medullary epithelial cells. J Immunol 1985; 134: 2971-2977.

33. Ripen AM, Nitta T, Murata S, Tanaka K, Takahama Y. Ontogeny of thymic cortical epithelial cells expressing the thymoproteasome subunit beta5t. Eur J Immunol 2011; 41: 1278-1287.

34. Murata S, Sasaki K, Kishimoto T, Niwa S, Hayashi H, Takahama $Y$ et al. Regulation of CD8+ T cell development by thymus-specific proteasomes. Science 2007; 316: 1349-1353.

35. Takahama Y, Takada K, Murata S, Tanaka K. beta5t-containing thymoproteasome: specific expression in thymic cortical epithelial cells and role in positive selection of CD8+ T cells. Curr Opin Immunol 2012; 24: 92-98.

36. Blanpain C, Horsley V, Fuchs E. Epithelial stem cells: turning over new leaves. Cell 2007; 128: 445-458.

37. Fuchs E. Skin stem cells: rising to the surface. J Cell Biol 2008; 180: 273-284

38. Nehls M, Pfeifer D, Schorpp M, Hedrich H, Boehm T. New member of the winged-helix protein family disrupted in mouse and rat nude mutations. Nature 1994; 372: 103-107.

39. Su DM, Navarre S, Oh WJ, Condie BG, Manley NR. A domain of Foxn1 required for crosstalk-dependent thymic epithelial cell differentiation. Nat Immunol 2003; 4: 1128-1135.

40. Weiner L, Han R, Scicchitano BM, Li J, Hasegawa K, Grossi M et al. Dedicated epithelial recipient cells determine pigmentation patterns. Cell 2007; 130: 932-942.

41. Garg S, Oran AE, Hon H, Jacob J. The hybrid cytomegalovirus enhancer/chicken beta-actin promoter along with woodchuck hepatitis virus posttranscriptional regulatory element enhances the protective efficacy of DNA vaccines. J Immunol 2004; 173: 550-558.

42. Corbeaux T, Hess I, Swann JB, Kanzler B, Haas-Assenbaum A, Boehm T. Thymopoiesis in mice depends on a Foxn1-positive thymic epithelial cell lineage. Proc Natl Acad Sci USA 2010; 107: 16613-16618.

43. Itoi M, Tsukamoto N, Amagai T. Expression of DII4 and CCL25 in Foxn1-negative epithelial cells in the post-natal thymus. Int Immunol 2007; 19: 127-132.

44. Pignata C, Fusco A, Amorosi S. Human clinical phenotype associated with FOXN1 mutations. Adv Exp Med Biol 2009; 665: 195-206.

45. Pignata C, Fiore M, Guzzetta V, Castaldo A, Sebastio G, Porta F et al. Congenital Alopecia and nail dystrophy associated with severe functional T-cell immunodeficiency in two sibs. Am J Med Genet 1996; 65: 167-170.

46. Pignata C, Gaetaniello L, Masci AM, Frank J, Christiano A, Matrecano E et al. Human equivalent of the mouse Nude/SCID phenotype: long-term evaluation of immunologic reconstitution after bone marrow transplantation. Blood 2001; 97: 880-885

47. Adriani M, Martinez-Mir A, Fusco F, Busiello R, Frank J, Telese $S$ et al. Ancestral founder mutation of the nude (FOXN1) gene in congenital severe combined immunodeficiency associated with alopecia in southern Italy population. Ann Hum Genet 2004; 68: 265-268.

48. Kushwaha R, Thodima V, Tomishima MJ, Bosl GJ, Chaganti RS. miR-18b and miR-518b Target FOXN1 during epithelial lineage differentiation in pluripotent cells. Stem Cells Dev 2014; 23: 1149-1156.

49. Dassule HR, Lewis $P$, Bei M, Maas R, McMahon AP. Sonic hedgehog regulates growth and morphogenesis of the tooth. Development 2000; 127: 4775-4785.

50. Burnley P, Rahman M, Wang H, Zhang Z, Sun X, Zhuge $Q$ et al. Role of the p63-FoxN1 regulatory axis in thymic epithelial cell homeostasis during aging. Cell Death Dis 2013; 4: e932.

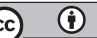

Cell Death and Disease is an open-access journal published by Nature Publishing Group. This work is licensed under a Creative Commons Attribution 4.0 International Licence. The images or other third party material in this article are included in the article's Creative Commons licence, unless indicated otherwise in the credit line; if the material is not included under the Creative Commons licence, users will need to obtain permission from the licence holder to reproduce the material. To view a copy of this licence, visit http://creativecommons.org/licenses/by/4.0 